\title{
Emerging preoccupations, developing lexicon
}

\author{
BRIAN POOLE
}

\author{
How the English language lexicon expands as the priorities \\ and concerns of speakers change
}

\section{Introduction}

'There is a very close link between the life of a society and the lexicon of the language spoken by it.' (Wierzbicka, 1997: 1).

A few decades ago it probably seemed, to proficient English language users, that if one was 'active' that would be sufficient to win plaudits from one's boss and to impress one's friends. After all, being active implies, amongst other things, that one's behaviour is 'characterized by busy or lively activity' (Oxford Dictionaries online). However, more recently it has begun to seem that activeness is not enough: one must be 'proactive'. Cooley (2016) provides readers with ten ways in which they can be more proactive at work. The promotion of proactiveness (or should that be proactivity?) seems, at least on the evidence of this extract, to require a liberal sprinkling of exclamation marks:

Proactivity requires that you be organized. That includes your mindset, your space, and of course, your schedule!

Set goals for yourself. Write them down! List everything that you want to accomplish! Set deadlines!

I happen to remember that the first time I consciously noticed someone using the word 'proactive' was in 1990. A search for 'proactive' via the Google Books Ngram Viewer (https://books. google.com/ngrams) provides evidence that the word did not really exist until after the Second World War and that its use increased quite sharply from about 1980 (see Figure 1). Does the emergence of the word 'proactive', presumably to fill a gap in the lexicon, indicate that over the years English-speaking communities have become more appreciative of those who act in anticipation rather than sitting idly by?

This article is about a small selection of words and phrases which show a similar pattern in the Google Books Ngram Viewer (based on data up to 2008). That is to say, each of them emerged some decades ago (mainly in the 1960s, 1970s, 1980s or 1990s) and has since been used with increasing frequency. I hit upon these particular lexical items purely by using my intuitions as a native speaker of British English and by trying to think of words or phrases that, to me, as an expatriate British man in his fifties, seem to be redolent of some aspect of the spirit

BRIAN POOLE is Head of
Teaching and Research
Standards at Majan
University College in
Muscat, Oman. He
previously worked in higher
education in the UK, South
Korea, Fiji, Singapore and
Turkey. He has long been
interested in English




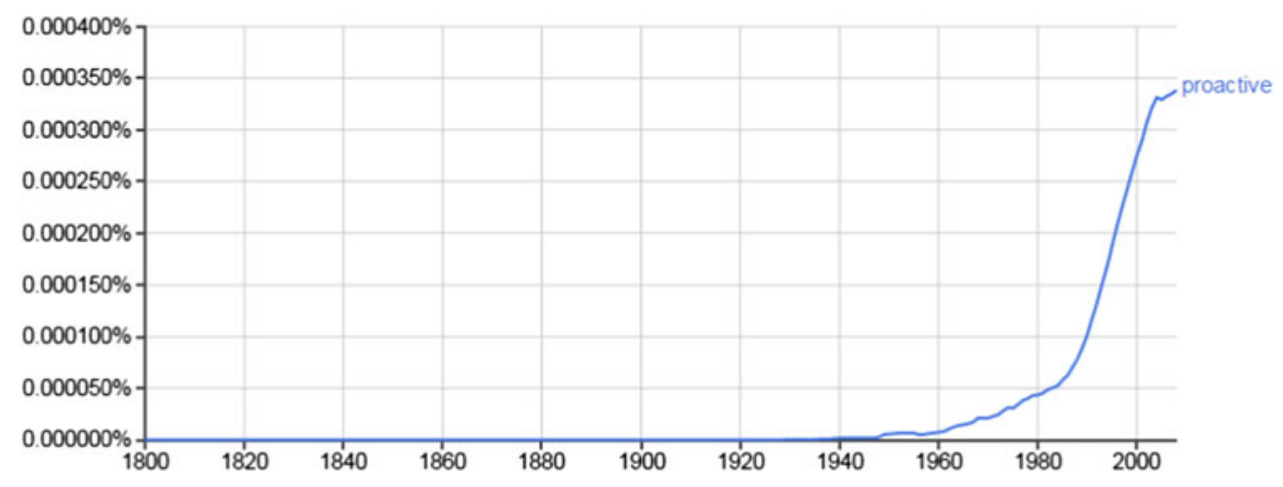

Figure 1. Google Books Ngram Graph for 'proactive'

of the age, the zeitgeist. It may also be the case that my approach owes something to that adopted by the literary critic and cultural commentator Raymond Williams in his famous 1976 book 'Keywords'. Overall, however, the selection is not at all 'scientific' or 'objective' and is likely to be influenced by some of my own prejudices and interests. Nevertheless, I think that the list, taken as a whole, provides us with at least a fleeting insight into some of the ways in which new words in the English language reflect the concerns of speakers in Anglophone societies.

Years in brackets after particular words or phrases indicate approximately when their use began to grow. Unless otherwise stated this pattern of growth has been continuous.

\section{The pleasures and pressures of disposable income}

In an online article on the British Library website entitled 'The Rise of Consumerism', White (n.d.) argues that 'shopping became an important cultural activity in the 18th century.' According to Google Books Ngram data, however, the word 'consumerism' itself only came into use around 1970, though its use has continued to increase since.

'Consumerism' is a term sometimes used in relation to consumer rights movements (Hilton, 2003). However, it can also describe a state of affairs 'in which many people formulate their goals in life partly through acquiring goods that they clearly do not need for subsistence or for traditional display' (Stearns, 2001: x). It therefore seems likely that the main reason for increasing use of this word is that huge numbers of relatively affluent people across the globe have in the past halfcentury or so begun to regard shopping, perhaps particularly in large shopping malls, as a pleasurable spare-time activity. Indeed, some of those individuals genuinely regard 'retail therapy' (emerging as a phrase from around the mid-1980s) as a means through which to shake off the troubles of the day. The rise of the lexical items 'consumerism' and 'retail therapy' appears to go hand in glove with the love affair with shopping. When, in 1961, a Yorkshire coal-miner won the presentday equivalent of more than $£ 3$ million on the football pools, his wife, Viv Nicholson, was famously quoted in the media as saying that it was her intention to 'spend, spend, spend!' Sizeable proportions of the UK adult population seem to share this tendency. In November 2000 Tracey McVeigh of the Guardian newspaper reported (McVeigh, 2000) that, in the view of researchers, ' 10 per cent of the population, and possibly 20 per cent of women, are manic, compulsive shoppers.'

There are, of course, other preoccupations that go along with an interest in acquiring consumer goods. One can be referred to by the rather dated expression 'keeping up with the Joneses' (emerging in the 1920s and peaking in the 1960s, according to Google Books Ngram data). In Britain there is a concentration on climbing the "property ladder', a term that gained traction in the 1980s and has grown in popularity ever since. As middleclass buyers move into areas which were previously rather more working-class, they cause 'gentrification' (1975). Alternatively, house purchases may be made as investments rather than as a means of securing a place to live. This is where 'buy to rent' (1980s) comes in. All of these developments might well be linked to 'Thatcherism' (circa 1980, but tapering off slightly in recent years).

A further way of keeping up with the Joneses is to make sure that the fixtures, fittings and interior 
decoration of one's house or flat are fashionable and up to date. A 'fitted kitchen' (1970) might help to achieve that aim, and perhaps also a 'master bedroom' (1970) with an 'en suite bathroom' (1980). To keep costs down the owner might decide to do part of the renovation work as a 'DIY' (1970) project.

Of course, in order to be able to buy anything, whether it be a fitted kitchen, clothes or a meal in a fancy restaurant, people need money (or, at least, a line of credit). It may help if, at work, you are 'upwardly mobile' (1960 onwards but recently tapering off) or if you have a 'credit card' (1960). Unfortunately, over-zealous shopping or poor management of personal finances may mean that your credit card gets 'maxed out' (1980). Then you may find yourself in need of a 'payday loan' (rising steeply since 1995) or perhaps even the local 'food bank' (1980). One 'downside' (1960) of the consumer society is that there are associated anxieties. Increasingly there is an attention to 'work-life balance' (rising sharply since 1995), whether individuals or societies achieve it or not.

For some individuals, there is a desire (or, perhaps, a dream) of becoming famous. The British journalist George Monbiot (2014), reporting a 2014 UK survey of children under the age of 10 , noted that 'British children no longer aspire to be train drivers or nurses - more than a fifth say they just want to be rich.' In the same survey $19 \%$ said they wanted to be famous. Someone aspiring to be famous could be described, often derisively, as a 'wannabe' (1987). The ambition might be to achieve the status of 'superstar' (1960) or 'supermodel' (1980). Alongside this there is a greater public interest in 'celebrity culture' (1980, but rising rapidly since 1995).

\section{Recreation and relaxation}

Google Ngram data shows that the phrase 'gym membership' has risen sharply since about 1990 . It seems that there is now a much greater interest than hitherto in having a 'six-pack' (1960) and in reducing the obviousness of one's 'love handles' (1980 onwards). Does a regular gym habit reduce stress? Or is it mainly exercise driven by narcissism? No doubt each individual gym-goer would answer differently, but the apparently greater interest in 'working out'2 may be partly caused by concerns about a 'sedentary lifestyle' (1980 onwards). Those who do not exercise much and are perceived to be sitting around all day tend to be dubbed 'couch potatoes' (1985).
A combination of diet and lack of physical activity seem to underlie the rise in the numbers of people who are 'clinically obese' (rising since 1970). One way of seeking to combat obesity which does not require a gym subscription is 'jogging' (up from 1970 to 1990 but now tapering off), but for that you will certainly need 'training shoes' (1970 onwards).

Whether jogging or going to the gym count as recreation is a moot point, but a host of lexical items have emerged in recent decades which seem to cluster around the notions of recreation and/or relaxation. There seems to be a need to 'destress' (1965 onwards) the mind and perhaps also to 'detox' (1970) the body. Some individuals might seek to achieve relaxation by smoking a 'spliff' (1970) or by 'hanging out' or 'chilling out' (both on the rise from 1980) with friends. Perhaps the consumption of 'craft beer' (1990) or even, being non-judgemental, a visit to a club specialising in 'lapdancing' (1990) might help in winding down? A 'long weekend' (1950) away perhaps a 'city break' (rising since 1985) - might also do the trick. Certainly if one is 'stressed out' (1980) or, as a student, suffering from 'exam stress' (1980) something needs to be done. Maybe an evening class on 'mindfulness' (rising since the 1980s) could be of benefit?

Unfortunately, some of those who find that they cannot cope with a work environment that constantly demands 'multi-tasking' (rising since 1980 but perhaps now tailing off) and leaves no scope for a 'power nap' (1980), react in ways which may be seen as negative. Feeling under pressure they may take to 'binge drinking' (1980) or succumb to 'eating disorders' (1980). Perhaps such people would be better off getting out of the 'rat race' (rising 1940 to 1970) and thinking instead about 'downshifting' (1970) to a simpler life.

\section{Fashion, face and food}

It is often argued (e.g. Djelic \& Ainamo, 1999: 625) that an Englishman, born in Lincolnshire but active in mid- $19^{\text {th }}$ century Paris, was the originator of haute couture. Charles Frederick Worth (1825-1895) was, among other things, the dressmaker for the wife of Napoleon III, Empress Eugénie of France. However, the phrase 'haute couture' has been more frequently used in English language texts since about 1950, on the evidence of Google Books Ngram data. This may reflect both greater affluence and an associated rise in interest about 'designer labels' (1980 but recently tapering off slightly). The phrase 'fashion 
victim' (1980) - perhaps not unrelated to haute couture - also shows a rising pattern. Various lexical items relating to enhancement or preservation of one's looks, such as 'facial scrub' (1975), 'moisturiser' (1975), 'men's skin care' (1980) and 'lip gloss' (early 1990s), have also seen increasing use.

Alongside the concern with looking good, English-speaking societies seem to have developed a greater interest in eating well, or eating to stay healthy. Lexical items such as 'organic produce' (1985), 'organic vegetables' (late 1980s), 'celebrity chef' (1980) and 'gastro pub' (2000) seem to have risen in popularity for those sorts of reasons. Similarly, 'barista' (1990) has been borrowed from Italian, though not normally with masculine and feminine plural forms as in the source language. The term 'vegan' rose from the 1960s to about 2000, while the compound adjective 'gluten-free' has been rising since about 1995 . The phrase 'peanut allergy' shows a sharp rise in use from 1985 onwards, reflecting the fact that, for instance, about $1 \%$ of people in the USA are allergic to peanuts (Sicherer, Muñoz-Furlong \& Sampson, 2003).

\section{Final remarks}

This short article has included selective examples of words and phrases showing a rising pattern in Google Books Ngram data over recent decades. It would certainly have been possible to focus on other areas of human activity: for example, it seems very likely indeed that lexical items from the world of technology such as 'tweet', 'vlog' or 'smartwatch' will have risen in use during the past few years. Similarly, close observers of British English will have noticed how 'train station' seems to be gaining ground over 'railway station' (certainly among younger speakers and writers, and perhaps under the influence of US English) and become aware of the arrival of the new verb 'mansplain', serving to denote the way in which (allegedly) men tend to 'explain' actually rather obvious things to women in a patronising manner.

Phenomena of this kind are obviously not confined to English. Gladkova (2008: 301) notes that 'Russia's opening to the world in the 1980s led to considerable changes in the lifestyle, mentality, attitudes and values of the people.' She goes on to link changes in values and mentality to linguistic changes when she states that 'These changes ... had a significant impact on the Russian language.' She provides such examples as press-reliz; butik and brifing, as well as the borrowing of English 'tolerant' to form the Russian noun tolerantnost.
However, in this article I have offered a few personal observations about the rise of words and phrases in Anglophone societies which seem to relate to increasing concentration on matters such as making or spending money, dealing with stress, retaining one's looks and staying healthy. These all appear to be preoccupations that loom large in English-speaking societies today and are reflected in changing patterns of lexical use. As Baugh and Cable (2002: 283) put it:

Words, being but symbols by which people express their ideas, are an accurate measure of the range of their thoughts at any given time. Words obviously designate the things a culture knows, and just as obviously the vocabulary of a language must keep pace with the advance of the culture's knowledge. The date when a new word enters the language is in general the date when the object, experience, observation, or whatever it is that calls it forth has entered public consciousness.

\section{Notes}

1 Though of course some references to 'six-packs' could well involve beer!

2 The phrase 'working out' does seem to be on the rise, but of course its multiple meanings cloud the issue. Consider, for example, 'working out' the solution to a problem.

\section{References}

Baugh, A. C. \& Cable, T. 2002. A History of the English Language. $5^{\text {th }}$ Edition. London: Routledge.

Cooley, A. M. 2016. 'Ten ways employees can be more proactive at work.' Online at $<$ http://www.careerealism. com/be-more-proactive-work/> (Accessed June 8, 2016).

Djelic, M.-L. \& Ainamo, A. 1999. 'The coevolution of new organizational forms in the fashion industry: A historical and comparative study of France, Italy, and the United States.' Organization Science, 10(5), 622-637.

Gladkova, A. 2008. 'Tolerance: New and traditional values in Russian in comparison with English.' In C. Goddard (ed.), Cross-Linguistic Semantics. Amsterdam: John Benjamins, pp. 301-329.

Hilton, M. 2003. Consumerism in Twentieth-Century Britain. Cambridge: Cambridge University Press.

McVeigh, T. 2000. 'One woman in five is a shopaholic.' The Guardian, $25^{\text {th }}$ November 2000.

Monbiot, G. 2014. 'Falling apart.' The Guardian, $14^{\text {th }}$ October 2014. Oxford Dictionaries Online. Online at $<$ http://www.oxforddictionaries.com/> (Accessed June 8, 2016).

Sicherer, S. H., Muñoz-Furlong, A. \& Sampson, H. A. 2003. 'Prevalence of peanut and tree nut allergy in the United States determined by means of a random digit dial telephone survey: A 5-year follow-up study.' Journal of Allergy and Clinical Immunology, 112(6), 1203-1207.

Stearns, P. 2001. Consumerism in World History: The Global Transformation of Desire. London: Routledge. 
White, M. n.d. 'The rise of consumerism.' Online at $<$ https:// www.bl.uk/romantics-andvictorians/articles/the-rise-ofconsumerism/ > (Accessed June 8, 2016).
Wierzbicka, A. 1997. Understanding Cultures through their Key Words. Oxford: Oxford University Press. Williams, R. 1976. Keywords. London: Fontana. 